\title{
"A vitória não é completa, mas é inevitável que virá": George Butler, o protestantismo e a laicização do Estado no Brasil
}

\author{
"The Victory Is Not Complete, But It Is Inevitably Coming": George \\ Butler, Protestantism and the Laicization of the State in Brazil
}

Rogerio de Carvalho Veras ${ }^{*}{ }^{* *}$

\section{RESUMO}

O artigo aborda o tema da laicização do Estado a partir das ações e dos discursos do missionário protestante George William Butler (1853-1919) nos primeiros dias após a proclamação da República. O objetivo é avaliar como esse personagem vivenciou e participou desse processo. Analisando seus relatórios, os conflitos políticos locais e as relações do missionário com agentes que elaboraram uma lei de separação Igreja-Estado no Maranhão, sua vida surge como uma via de acesso para o entendimento deste processo e dos sentidos que os protestantes lhe desejavam imprimir. Assim, destaca-se a importância da análise micro-histórica para se perceberem os indivíduos não apenas como receptores de transformações macrossociais, mas como agentes dessas mudanças.

Palavras-chave: George William Butler; protestantismo; laicização; espaço público.

\section{Abstract}

The article addresses the theme of the laicization of the State based on the actions and speeches of the Protestant missionary George William Butler (1853-1919) in the first days after the proclamation of the Republic. The objective is to evaluate how this character experienced and participated in this process. By analyzing his reports, the local political conflicts and the missionary's relations with agents who drafted a law of church-state separation in Maranhão, his life appears as a form of access to understand this process and the meanings that Protestants wanted to imprint on it. Thus, the importance of micro-historical analysis stands out to perceive individuals not only as receivers of macro-social transformations, but as agents of these changes.

Keywords: George William Butler; Protestantism; Laicization; Public Space.

\footnotetext{
* Universidade Federal do Maranhão (UFMA), Imperatriz, MA, Brasil. rogerio.veras@ufma.br $<$ https://orcid.org/0000-0001-8821-8001>

** O presente trabalho foi realizado com apoio da Coordenação de Aperfeiçoamento de Pessoal de Nível Superior - Brasil (CAPES) - Código de Financiamento 001.
} 


\section{INTRODUÇÃO}

Nas últimas décadas, aumentou o interesse de historiadores e demais cientistas sociais a respeito da relação entre Estado e religião no Brasil, especialmente diante do atual cenário político no qual igrejas evangélicas, ancoradas em seu crescimento numérico, provocaram transformações significativas no espaço público (atuando em instâncias políticas, mídias de massa, movimentos sociais, etc. $)^{1}$.

Muitas dessas pesquisas buscam compreender este tema servindo-se do diálogo ou da problematização da tese da secularização atribuída a Weber embora ele mesmo tenha utilizado bem pouco a expressão em sua obra. Apesar das críticas possíveis à noção de secularização (especialmente quando tomada em seu sentido teleológico ou normativo, considerando-se o suposto malogro do processo de secularização, tendo-se em vista a permanência e a pluralização religiosa no mundo contemporâneo), retomo-a compreendendo-a, conforme Antônio Flávio Pierucci, como um processo fático existente nas sociedades ocidentais, onde quer que o domínio da lei tenha se emancipado da religião (Pierucci, 1998).

Neste sentido, a secularização, em sua expressão jurídico-política, diz respeito ao declínio da legitimidade religiosa, fundada na "lei divina", oferecida pelo poder sacerdotal aos poderes políticos, e ao triunfo de um novo sistema de legitimidade fundado na "lei humana", esta criada e passível de alteração desde que atendidos os procedimentos de um sistema representativo. A fórmula jurídico-política da separação Igreja-Estado consubstancia um processo no qual a lei se emancipa da tutela da religião (o aspecto fático) e permite ao poder do Estado não estar a serviço de nenhuma instituição ou grupo religioso de seu território (o aspecto de doutrina política). Portanto, nesse último sentido, a secularização é também uma agenda política dos Estados liberais modernos, favorecendo a liberdade de consciência e a pluralidade religiosa como esteios da nova ordem democrática ${ }^{2}$.

Todavia, a secularização mantém-se como um processo em aberto, definido e redefinido constantemente segundo as relações de força entre o poder político e o religioso nos Estados liberais modernos, o que explica a diversidade efetiva das formas dos Estados secularizados ${ }^{3}$. Assim, a noção de secularização remete a uma análise macrossocial, a um processo de longa duração cuja expressão formal, objetivada, estaria na conformação jurídico-política da separação Igreja-Estado, em seus diferentes contextos históricos.

No Brasil, os anos finais do Império e o início da República são um pe- 
ríodo fértil para o estudo das especificidades dos rumos nacionais na conformação de um Estado laico ${ }^{4}$. Entre tantas dimensões desse processo, uma via algo inusitada foi se apresentando ao longo de minha pesquisa sobre a trajetória do missionário protestante e norte-americano George William Butler (18531919) (Véras, 2018).

Esta personagem viveu no Nordeste brasileiro nesses anos de transição da Monarquia à República (1882-1919). Ele chamou a minha atenção pelo seu envolvimento nas disputas religiosas e políticas para a redefinição da ideia de liberdade religiosa. Uma luta que reivindicava a separação entre a Igreja Católica e o Estado. Assim, percebi, no estudo deste sujeito, a possibilidade de obter uma nova perspectiva sobre o processo macro de construção do Estado laico, ou da laicização do Estado no Brasil.

Se observarmos a historiografia sobre o processo de laicização do Estado no Brasil, veremos que, de um lado, predomina uma interpretação que atribui a separação Igreja-Estado aos agentes políticos liberais-positivistas-anticlericais, por vezes, minimizando uma árdua negociação e uma gradual acomodação entre estes e seus oponentes (principalmente ultramontanos e outros intelectuais católicos); de outro, uma interpretação teleológica, em uma espécie de evolução natural da legislação liberal que levaria ao fim do monopólio católico sobre o Estado ${ }^{5}$.

Há ainda os historiadores (principalmente católicos) que destacaram o protagonismo do clero, especialmente de Dom Antônio Macedo Costa, na redefinição legal da separação Igreja-Estado após a Proclamação da República. Dom Macedo, então Bispo Primaz do Brasil, negociou com os positivistas, intermediado por Rui Barbosa (seu ex-aluno), e atuou para minimizar as perdas da Igreja Católica ${ }^{6}$. Por outro lado, os historiadores do protestantismo (geralmente evangélicos) destacaram o papel das igrejas protestantes como uma das forças de pressão (ao lado de republicanos, positivistas e espíritas, entre outros) pela laicização do Estado ${ }^{7}$, adensando o contexto ideológico pela separação.

Minha inquietação era de que o papel do conflito entre agentes do protestantismo e do clero católico, especialmente nos instantes decisivos da separação Igreja-Estado, precisava ser melhor delimitado. Neste impulso investigativo, procurei compreender como os agentes do protestantismo, principalmente os missionários estrangeiros, agiram em favor dessa solução jurídico-política. Observar as ações de George Butler e seus aliados, a partir da documentação produzida durante sua estadia no Maranhão (1883-1892), mostrou-se uma via 
de acesso privilegiada para fornecer um novo olhar sobre como se deu a separação Igreja-Estado no Brasil.

Deste arrazoado inicial certamente emergem ao leitor duas questões: 1) como um obscuro missionário protestante e os conflitos dos quais participou, em uma longínqua província do Norte, contribuíram para a separação Igreja-Estado?; 2) e o que sua ação e seus discursos podem revelar sobre o papel do protestantismo na conformação do espaço público republicano? Portanto, razoáveis questionamentos que põem em foco o necessário, mas difícil, jogo da "alternância das lentes" entre o micro e o macro ${ }^{8}$.

A fim de encaminharmos as respostas, é necessário realizarmos uma narrativa dos acontecimentos nos primeiros dias da República no Maranhão, cujos episódios, ainda desconhecidos pela historiografia nacional, mostraram-se importantes para a conformação jurídica da laicização do espaço público na inauguração do novo regime.

\section{A Proclamação e as leis de SEPARAÇÃo IGREJA-Estado No MARANHÃo}

Após três dias da Proclamação da República, e negados os primeiros boatos de uma contrarrevolução monárquica, deu-se a instalação do governo provisório republicano no Maranhão. Era o dia 18 de novembro. Antes, no dia 17, ocorreu um levante, composto por ex-escravizados temerosos do retorno da escravidão com a queda do Império, gerando forte repressão policial com muitos feridos e mortos nas ruas de São Luís?

Passado este confronto, e ainda sob a repercussão dele, a junta do governo provisório, em quase um mês no exercício do poder, tomou medidas de perseguições a representantes populares e mesmo contra membros das elites políticas, que aumentaram as desconfianças e os conflitos internos aos grupos dirigentes locais. A instabilidade foi a tônica dos primeiros meses da República no Maranhão, e nem a nomeação do novo governador pelo governo central foi capaz de restaurar a tranquilidade. Em meio aos conflitos, a questão da separação da Igreja-Estado tornou-se um dos combustíveis da crise.

Dos sete membros do governo provisório, há dois atores políticos fundamentais nesses tempos de transição e crise: o presidente da Junta Governativa, coronel João Luís Tavares, comandante do $5^{\circ}$ Batalhão, e o jornalista, advogado e ex-parlamentar Francisco de Paula Belfort Duarte, uma espécie ideólogo do novo governo. Ambos tinham suas esposas filiadas à única igreja protestante 
no Maranhão, a Igreja Presbiteriana de São Luís, dirigida pelo missionário norte-americano George William Butler.

No dia 06 de dezembro, a Junta Governativa determinou a "liberdade de culto no Maranhão", fazendo deste Estado o primeiro a tomar tal medida. Eis o decreto:

Attendendo, finalmente, a que a liberdade de culto e religiões carece da maior expansão e resume em si uma das mais formaes aspirações da Republica, [a Junta do Governo Provisório] resolve decretar o seguinte: É garantido neste Estado o direito de reunião, e nesta a livre enunciação do pensamento politico ou religioso de cada um, sem outro limite senão a ordem e a moral publica (Governo Provisorio do Estado..., 1889, p. 2).

Dias depois, a 18 de dezembro, com a chegada do novo governador nomeado pelo governo central, Pedro Augusto Tavares Junior, este decreto foi revogado, juntamente com as outras medidas da Junta Governativa. Todavia, passados apenas cinco dias, no dia 23 de dezembro, Pedro Tavares editou novo decreto determinando não só a liberdade de culto, como também a extinção dos subsídios à Igreja Católica:

Considerando que a liberdade de consciencia é uma das maximas fundamentaes do regimen republicano; Considerando que é da essência desse immortal direito do pensamento e da razão a perfeita e a mais completa igualdade dos diversos cultos; e Considerando que este Estado não pode nem deve demorar a declaração do salutar princípio e a sua sincera aplicação. Resolve: Art. $1^{\circ}$ É reconhecido e garantido a todas as seitas e religiões o pleno exercicio dos seus cultos, podendo edificar os seus templos com a forma interior e exterior que bem convier ou parecer aos interessados, salva qualquer futura deliberação dos poderes federaes a respeito. Art. $2^{\circ}$ Fica desde já extinctos os subsídios até hoje prestados ao Asylo de Santa Theresa e ao Seminario [...]. Art $3^{\circ}$ Fica igualmente extincta a verba - Culto Publico - e suspensos quaisquer pagamentos [...]. Art. 4o São dispensados dos seus empregos ou comissões os padres e sacerdotes [...] (Gazetilha, 1889, p. 3).

A medida do novo governador gerou rápida reação dos ministros do governo central Aristide Lobo, ministro do interior, e Rui Barbosa, ministro da fazenda, como se percebe pela troca de telegramas ${ }^{10}$ :

Rio, 24. - Governador do Maranhão. - O governo federal não pode aprovar os vossos últimos decretos sobre matéria religiosa. Deveis sustar imediatamente a 
execução dos vossos decretos attinentes a este assumpto [...]. Temos interesses geraes que atender n’esta matéria. Aguardai instrucções posteriores. Cumpri o que vos determino. - Ministro do Interior.

Rio, 24. - Governador. - Com espanto recebemos hoje notícia seu acto decretando separação Egreja estado no Maranhão [...]. Reflita V. Ex. gravidade enorme deste precedente e suas consequências, se outros Estados seguissem exemplo. Liberdade de Cultos estará decretada poucos dias. Mas separação Egreja simples medida interesse politico cuja solução envolve responsabilidade federal [...]. Ruy Barbosa.

Em seguida, vem a enérgica resposta do Marechal Deodoro: "Rio, 24 governador - Anulle seu decreto negócios eclesiásticos; medida extemporânea, inconveniente; trata-se organisar projecto lei separação igreja estado modo aconselhado prudencia actualidade. - Deodoro."

No dia seguinte, Pedro Tavares justificava-se, respondendo a Rui Barbosa não sem uma certa ironia, fazendo uso da mesma frase "Com espanto recebi..." com que este iniciara seu telegrama:

S. Luis, 25. - Dr. Ruy Barbosa, ministro das finanças [...]. Com espanto recebi telegrama de V. Ex. no qual diz que separei Igreja do Estado. Queira lêr com atenção o meu decreto em sua integra. Declarei e garanti unicamente a liberdade de cultos. No decreto suspendi subsídios e subvenções onerosas ao orçamento d'este estado [...]. O meu acto foi bem recebido aqui e ainda não ouvi uma reclamação contra elle.

Pedro Tavares argumentava que seu ato legislativo não significava a separação Igreja do Estado, apenas a liberdade de cultos e a liberdade para outras religiões construírem seus templos. Afirmava ainda que os artigos da lei relativos às instituições religiosas subvencionadas tratavam de matéria orçamentária de exclusiva competência do governo do estado, cuja carência financeira fazia necessário desonerar os cofres públicos dos subsídios à Igreja Católica. Por sua, vez, os ministros de Marechal Deodoro aconselhavam que o governador tivesse prudência e revogasse a medida, alegando tratar-se de matéria de interesses gerais ou de "interesse político de responsabilidade federal", e deixando entrever que o governo estudava a melhor maneira de fazer a separação sem ferir demasiadamente os interesses da Igreja (Tavares Junior, 1890, p. 3).

Com efeito, durou pouco tempo a vitória dos partidários da separação, apesar da insistência de Pedro Tavares, que não retrocedeu do ato. Quatro dias 
depois da medida ser considerada "extemporânea" e "inconveniente" por Marechal Deodoro, o mesmo ordenou ao ex-presidente da ex-junta governativa - Tenente-coronel João Luiz Tavares, um dos desafetos do novo governador - que anulasse o decreto. João Luiz Tavares fez publicar n’O Globo a seguinte ordem: "Em virtude de ordem telegráfica do cidadão marechal Manoel Deodoro da Fonseca, n’esta data faço publica a annullação do decreto do Governador d'este Estado, separando a Igreja do Estado." (Tavares, 1889, p. 3).

Antes disso, o governador Pedro Tavares Júnior chegou a telegrafar a Deodoro para explicar sua medida "de acordo com o princípio liberal e democrático da liberdade de cultos", mas não foi atendido, no que terminou por dizer, como tantos outros decepcionados com os rumos da Revolução: "a minha República está longe de se parecer com esta"11. Desautorizado pelo governo federal, restou-lhe pedir exoneração, deixando o cargo já nos primeiros dias de janeiro de 1890 (Lima, 2010a, p. 37).

O periódico católico Civilisação, no dia 04 de janeiro, saudou a intervenção de Marechal Deodoro anulando o decreto. A posição do jornal foi defender que tal medida só poderia ser tomada por uma Constituinte, questionando o porquê de tal urgência em decretar a separação, e criticou o fato de o Maranhão ser "uma excepção sem motivo plausivel", em que se "nivelasse o Catholicismo com as seitas mais extravagantes". Por fim, o editorial, em tom um tanto ameaçador, deixa claro o entendimento da hierarquia católica sobre a matéria: "A boa política aconselha que se mantenha os direitos do Clero, cuja influência no seio da sociedade brazileira é maior do que se pensa”. E conclama os católicos a "protestar contra a espoliação dos privilégios, de que justamente gosa a Igreja Catholica” (A Religião do Estado, 1890, p. 1).

Em artigo de despedida ao ex-governador Pedro Tavares, no dia 08 de janeiro de 1890, o jornal $O$ Globo acrescenta à celeuma com o governo central uma trama de bastidores que trabalhou para a queda de Tavares: "Tramou-se na sombra contra s. exc; e os tramas iniciados nas sachristias tiveram êxito momentâneo" (Parte amanhã para..., 1890, p. 2).

No dia 30 de janeiro, dois dias após ter publicado seus telegramas trocados com as autoridades do governo central, Pedro Tavares Júnior deu a sua versão sobre os fatos que o levaram a pedir a exoneração do cargo. Publicou um artigo na Gazeta de Notícias no qual atribuiu a trama de sua demissão a outros autores: os membros da ex-junta governativa, especialmente João Luiz Tavares, a quem "incontestavelmente cabe a principal responsabilidade d'esses desmandos”, como uma espécie de retaliação pela anulação das medidas da junta (Tavares Junior, 1890, p. 3). 
Entre as medidas anuladas estava o primeiro decreto de "liberdade de culto no Maranhão" de 06 de dezembro. Pedro Tavares Junior explicou esta revogação argumentando que este "decretava a liberdade de cultos e illegalmente a separação da Egreja do Estado, visto como entrava pelo orçamento geral e extinguia as côngruas dos parochos, etc." (Tavares Junior, 1890, p. 3, grifo do original). Todavia contraditoriamente reeditou a medida com nova feição, justificando-a não exatamente por causa de suas convicções ideológicas, fossem positivistas ou republicanas, mas devido a ter sofrido pressões bem mais concretas:

No Maranhão, sabe-se, não existe espirito religioso ou clerical. O que existe lá, é uma numerosa communhão protestante, composta em sua grande maioria, segundo ouvi dizer, de brasileiros e estrangeiros distinctos, porque são laboriosos e moralisados. Com a promulgação do meu decreto anulando os actos da junta, nos quaes estava comprehendido esse sobre liberdade de consciencia, eis que se me enche o palácio de comissões protestantes, para inquirirem das minhas intenções, e communicarem-me que as igrejas já haviam feito para os Estados Unidos do Norte encomenda do material para seus templos. (Tavares Junior, 1890, p. 3).

Portanto, Pedro Tavares Junior relata que havia no Maranhão uma "numerosa communhão protestante" composta de "brasileiros e estrangeiros distinctos", que eram também "laboriosos e moralisados". Estes protestantes foram recebidos no palácio governamental e reivindicaram a manutenção do seu direito de "liberdade de consciência". Ademais, por já terem feito encomenda aos Estados Unidos para seus templos, Pedro Tavares achou por bem "não arrancar a uma comunhão religiosa um direito sagrado, que regular ou irregularmente lhe havia sido conferido e em cuja posse ella já se achava!" (Tavares Junior, 1890, p. 3).

Essa explicação que ele ofereceu de não ter retrocedido diante das pressões do presidente marechal Deodoro vincula-se, vale ressaltar, à política local e sua imbricação com interesses religiosos bem concretos, ou seja, à pressão de "uma numerosa comunhão protestante" existente na capital do Maranhão, composta de "brasileiros e estrangeiros distinctos".

Essa percepção dos próprios agentes históricos, de que os interesses religiosos estavam por trás das idas e vindas da legislação concernente à separação Igreja-Estado no Maranhão, evidencia que, sobrepondo-se a uma disputa ideológico-política entre positivistas e ultramontanos, havia nesta província uma declarada disputa entre católicos e protestantes pela influência sobre as 
autoridades locais, cujo objetivo era orientar a redefinição normativa das relações entre as religiões e o novo Estado republicano.

Os relatórios de George Butler enviados às igrejas norte-americanas também apontam neste sentido. Ao acompanhar, por estas fontes históricas, as ações de George Butler e a sua rede de relações no Maranhão durante a transição para a República (1883-1992), percebi que a sua ação foi mais efetiva do que uma difusa e abstrata pressão ideológica pela separação Igreja-Estado.

Há indícios de que a relação estreita dos membros da junta provisória com o protestantismo e os protestantes tenha contribuído para a primazia da medida "extemporânea" (como disse o Marechal Deodoro) no Maranhão. Segundo os relatórios de George Butler, ele e outros protestantes estavam diretamente envolvidos na questão. Escrevendo em janeiro de 1890, o missionário diz: "Nós temos ficado algo extremamente ansiosos com o projeto de lei da Liberdade de Culto, pois envolve a permanência ou a demissão dos cargos governamentais de um bom número de pessoas da nossa Igreja e amigos"12.

A importância da disputa do discurso público entre católicos e protestantes pela definição da legislação de separação é também um entendimento expresso pelo missionário norte-americano. No mesmo relatório de janeiro de 1890 , ele diz ter assegurado $\$ 1,500$ (mil e quinhentos dólares) para ajudar um amigo do evangelho a comprar uma imprensa e, ao mesmo tempo, evitar que tal maquinário caísse nas mãos do "partido católico". Em seguida, diz ter recebido do editor o seguinte telegrama: "Janeiro 10. A igreja foi separada do estado, igualdade de cultos proclamada, e subversão [sic] (subsídio) para qualquer religião proibida. Parabéns. Duarte"13. Fica claro que o amigo do evangelho era Paula Duarte, e a ajuda financeira levantada possibilitaria publicar, por aquele jornal, a perspectiva protestante em defesa da separação Igreja-Estado, daí o esforço de evitar que o maquinário fosse absorvido pelo clero.

O telegrama de Paula Duarte corrobora esse entendimento. Afinal, por que teria Paula Duarte parabenizado George Butler pelo decreto de separação do governo central? Seria apenas por ter sido ele e o protestantismo beneficiados pela medida? Ou seria o reconhecimento de que George Butler estava trabalhando pela lei de separação no Maranhão?

Em outro artigo, George Butler fornece mais indicativos de seu grau de envolvimento no caso. Ele faz uma narrativa dos acontecimentos do dia 15 de novembro no Brasil e, ao final, identifica-se com aqueles que agiram pela promulgação das primeiras leis de separação editadas em dezembro, no Maranhão. Diz ele: "O Estado do Maranhão tentou tomar a frente na separação da igreja e estado, mas o governo central revogou e rescindiu nossa ação" (grifo nosso) ${ }^{14}$. 
O decreto n. 119-A do governo central, de 07 de janeiro de 1890, foi promulgado garantindo a separação Igreja-Estado, com a igualdade entre as religiões, como defendiam os republicanos e positivistas ortodoxos ${ }^{15}$, e sem "privilégios" para a Igreja Católica, ou seja, nos moldes da legislação ensaiada primeiramente no Maranhão. É possível interpretarmos o telegrama de Paula Duarte como reconhecimento de que George Butler, os protestantes ("pessoas de nossa igreja") e seus aliados ("amigos do evangelho") haviam trabalhado por aquela formatação da legislação.

Tudo isso demonstra que a legislação de separação entre a Igreja e o Estado no Maranhão não foi apenas o resultado da disputa dos republicanos anticlericais e positivistas ortodoxos contra os clérigos católicos. Há também um importante papel desempenhado pelo grupo protestante, agindo na forma do que hoje chamamos de um grupo de pressão política.

Isso não é casual, pois os principais atores políticos locais se entrelaçavam aos protestantes e, logo, aos conflitos entre protestantes e católicos. De certa maneira, e de forma não planejada, devido a essa forte vinculação, o Maranhão tornou-se o pioneiro na separação Igreja-Estado, e uma espécie de balão de ensaio da configuração da lei federal de separação ${ }^{16}$ - publicada apenas dez dias após a revogação dessa lei no Maranhão ${ }^{17}$ - e de suas repercussões ${ }^{18}$.

É importante lembrarmos que não havia uma clareza na forma como se daria a separação entre a Igreja e o Estado. A formatação da lei de 07 de janeiro de 1890 se deu menos de dois meses após a Proclamação, e as normas maranhenses de dezembro foram as primeiras aparições legislativas cujo formato expressava uma ideologia mais radical do Estado laico (em comparação com as propostas católicas de preservação dos seus privilégios), que advogava a separação sem subsídios.

Por outro lado, as fontes nos permitem perceber que essa reinvindicação dos protestantes não era exatamente por seu fervor às formas estatais modernas ou por seu amor pela igualdade, pela liberdade e pela democracia, mas por interesses bem mais conservadores em relação ao tradicional papel da religião na socieda$\mathrm{de}^{19}$, como se observa noutro artigo escrito por George Butler: $O 15$ de novembro.

\section{Os DOIS “15 DE NOVEMBRO” \\ E O PROJETO DE HEGEMONIA PROTESTANTE}

No início de 1890, o missionário resolve explicar aos leitores das Igrejas estadunidenses o que havia ocorrido no Brasil no último mês de novembro. 
Ele escreve um artigo intitulado "O 15 de novembro", e inicia seu texto lamentando a notícia da instalação de uma Universidade Católica na capital dos Estados Unidos, no mesmo dia 15 de novembro de 1889: "Plantar bem no coração de uma nação protestante livre, uma universidade Romana, aliás, o símbolo da escravidão mental e política, é algo que não é facilmente esquecido"20. Em seguida, deseja compensar esta notícia com as seguintes observações sobre o 15 de novembro do Brasil:

Se os amantes da Liberdade Cristã deploram o avanço do papado em Washington, no Brasil eles se regozijam com grande e excessiva alegria pela queda do poder monárquico e papal. Nós estamos plenamente conscientes de que a vitória não é completa, mas é inevitável que virá21 .

Mas o que seria a vitória completa e inevitável? Ao final do artigo, ele esclarece: "Tanto quanto eu percebo, estão próximas as notícias de separação da Igreja e do Estado - a igualdade de religiões"22. Fica evidente que este texto fora escrito antes do decreto de separação promulgado em 07 de janeiro de 1890. Porém, surge aqui um aparente paradoxo: como pode o missionário desejar a liberdade religiosa e igualdade de religiões no Brasil, mas rejeitar o mesmo para a sua terra natal? Será que isso não lhe pareceu francamente contraditório?

Com efeito, não. Isso porque, segundo a lógica de George Butler - assim como para a ideologia missionária de muitos de seus leitores no Brasil (outros missionários) e nos Estados Unidos (as elites eclesiásticas e os adeptos das igrejas protestantes) -, catolicismo e liberdade eram conceitos antitéticos. O catolicismo era (e tinha que ser) representado como "símbolo da escravidão mental e política" para justificar a missão, por isso os "amantes da Liberdade Cristã deploram o avanço do papado" no coração de uma "nação Protestante livre", enquanto se regozijam com a queda da monarquia e do papado no Brasil.

Na perspectiva do missionário, a Proclamação da República era somente um primeiro passo necessário à "vitória completa" das missões protestantes. Pois, seguindo a sua linha de raciocínio, que entendia catolicismo e protestantismo não apenas como opções de foro privado, mas como representantes de éticas políticas antagônicas, a igualdade de religiões não poderia ser o objetivo final das missões protestantes no Brasil. A propalada defesa da "igualdade de religiões", presente nas fontes missionárias protestantes durante sua inserção no século XIX, não era um fim em si, mas um recurso retórico cujo objetivo era deixar o espaço público livre de restrições normativas ao projeto protestante de hegemonia política e cultural sobre a sociedade ${ }^{23}$. 
Em outras palavras, o discurso republicano de secularização da esfera pública, de laicização e da igualdade das religiões, existente nas disputas pela reconfiguração do espaço público ante a eminente queda da monarquia, foi convenientemente encampado pela minoria religiosa protestante no Brasil, como uma etapa para a realização de um projeto de maioria: a hegemonia protestante sobre o espaço público na nova ordem política republicana.

$\mathrm{O}$ artigo de George Butler acaba por ser revelador de uma visão de mundo compartilhada pelo seu grupo religioso ${ }^{24}$, segundo a qual o catolicismo era representado como inadequado à nova ordem moderna e republicana, e somente o protestantismo seria capaz de dar fundamentos compatíveis aos Estados republicanos.

Esse projeto de maioria, aspirado pela minoria protestante, estava bem claro para a Igreja Católica. E este é um aspecto que não pode ser negligenciado quando examinamos os discursos do clero católico nesse momento de indefinições, após a proclamação, e de conformação do espaço público republicano. Pois, se a separação era dada como certa - e há muito até mesmo desejada por setores do clero, como forma de obtenção da autonomia perante o regalismo imperial -, os esforços do discurso clerical concentraram-se em salvaguardar a primazia da Igreja Católica sobre a sociedade e o Estado, na condição de religião da "alma nacional", da maioria, dos "costumes" e da "tradição" brasileira, claramente firmando posição contrária às ambições de seu principal concorrente no campo religioso, o protestantismo ${ }^{25}$.

As fontes deixam claro que a concorrência com o protestantismo não estava ausente das preocupações do clero na formatação que ele procurava dar ao novo regime. É importante percebermos que logo após os decretos do Maranhão, as reações do clero local não foram tanto contra a separação do Estado e da Igreja Católica. O principal temor dos primeiros discursos católicos era o perigo do nivelamento "com seitas extravagantes" (A Religião do Estado, 1890, p. 1).

Após a promulgação do decreto de separação do governo central, o jornal clerical Civilisação mostrou-se ainda mais contundente na afirmação de que o decreto fora fruto de uma pressão das "seitas enraizadas no Brasil"26 (uma referência que mobiliza um imaginário pré-existente, especialmente contra o protestantismo):

Se as seitas, que sitiaram o governo provisório, e dele arrancaram o Decreto de separação da Igreja do Estado, não conseguirem a ruína da Religião Catholica por meio da fome, não se esquecerão de outras medidas opressoras, e fabricarão 
novas cadeias para tolher-lhe o movimento progressivo. A lucta será então medonha e produzirá nas consciencias delicadas angustias, que a pena é impotente para descrevel-as antecipadamente (A Religião do Estado, 1890, p. 2).

Portanto, para o clero católico estava em jogo não uma abstrata ideia de liberdade ou igualdade religiosa, mas uma luta pela hegemonia política e ideológica sobre a sociedade. Se, naquele momento, a proposta dos republicanos e positivistas ortodoxos por um espaço público laicizado (sob a fórmula "religiões livres no estado leigo") era vitoriosa, e isso favorecia os protestantes sendo eles próprios seus articuladores -, era necessário reagir, apresentando uma alternativa clara a ser empunhada nas próximas batalhas.

Propuseram, então, como contraponto, a formação de um espaço público moderadamente laicizado, no qual a Igreja Católica apropriava-se de autonomia perante o poder político e, ao mesmo tempo, mantinha seus privilégios perante outras religiões. Em suma, liberdade, mas sem igualdade. Foi essa a tônica da luta do clero católico, liderado pelo agora Bispo Primaz D. Antonio Macedo Costa, nos debates do projeto de Constituição em 1890/189127.

Essa luta da Igreja Católica pela liberdade sem igualdade entre as religiões, durante os primeiros debates da Constituição Republicana, já é bastante conhecida pela historiografia. É, no entanto, surpreendente que muitos analistas não tenham dado muita atenção ao papel dos protestantes ${ }^{28}$, uma vez que eram os principais concorrentes da religião majoritária e possuíam um projeto de hegemonia sobre a sociedade a ser efetivado após a Proclamação da República. Os protestantes (missionários estrangeiros e pastores brasileiros) exerceram pressão sobre os agentes do Estado republicano recém instalado, reivindicando a adoção de uma fórmula de organização do espaço público que advogasse pela igualdade entre as religiões. Uma fórmula que, destacamos, embora concordasse com as convicções de boa parte dos homens que chegaram ao poder em 15 de novembro de 1889, nem por isso era unânime e incontestável, embora tenha saído formalmente vitoriosa ${ }^{29}$, restando ainda ao historiador deslindar os caminhos dessa vitória e o modo como efetivamente ocorreu.

\section{CONSIDERAÇÕES FINAIS}

Esta pesquisa sobre a vida desse obscuro missionário norte-americano, suas ações e seus aliados, nesse momento capital da formação republicana, objetiva ser uma contribuição neste sentido. Quando inserimos essa biografia no contexto de suas relações com os agentes políticos que tiveram a primazia de elaborar 
uma lei de separação no Maranhão - assentada nos mesmos princípios da liberdade e da igualdade religiosas em que se daria a norma constitucional -, ela surge como um elo importante para o entendimento deste processo.

A trajetória de George Butler no Maranhão revelou que o protestantismo foi uma força social e política efetiva na configuração da laicização do Estado brasileiro consagrada na Constituição de 1891. Porém, esclarece também que os esforços dos agentes protestantes visavam, em última instância, não a modernização política, a ampliação democrática ou o pluralismo religioso, mas a substituição da religião católica pelo protestantismo na hegemonia sobre a sociedade e o Estado ${ }^{30}$.

Assim, embora George Butler e seus aliados atuassem numa distante província do Norte, sua intervenção no processo da laicização, isto é, da forma legal como se deu a separação entre Igreja e Estado no Maranhão, teve uma repercussão que atingiu o centro do debate nacional nos primeiros dias da República. Isso porque as leis de separação que surgiram no Maranhão em dezembro de 1889 (e pelas quais os protestantes se mobilizaram) pressionaram, com um fato jurídico-administrativo, os agentes do poder político nacional a definir com urgência a forma legal da laicização em âmbito federal.

Em outras palavras, a vida de George Butler nesta conjuntura permitiu-nos vislumbrar elos entre o nível micro e o macro, isto é, o papel de um agente religioso e de seus aliados na conformação do espaço público laico. Assim, este estudo nos possibilitou "discernir [...] o papel ativo do indivíduo que antes parecia simplesmente passivo ou indiferente" (Levi, 1992, p. 160): uma forma de percebermos os indivíduos não apenas como receptores de transformações macrossociológicas, mas como agentes dessas transformações na sociedade.

\section{REFERÊNCIAS}

A RELIGIÃO DO ESTADO. Civilisação, São Luís, p. 1, 4 jan. 1890.

A RELIGIÃO DO ESTADO. Civilisação, São Luís, p. 2, 18 jan. 1890.

AZZI, Riolando. D. Antonio de Macedo Costa e a posição da Igreja do Brasil diante do advento da República em 1889. Síntese, v. 3, n. 8, pp. 45-69, 1976.

BARROS, Roque Spencer M. de. Vida Religiosa. In: HOLANDA, Sérgio Buarque de (Org.). História Geral da Civilização Brasileira. O Brasil Monárquico: declínio e queda do Império. 5a Ed. Rio de Janeiro: Bertrand Brasil, 1997. pp. 317-337.

BRUNEAU, Thomas C. Catolicismo brasileiro em época de transição. São Paulo: Edições Loyola, 1974. 
BURITY, Joanildo A. Desconstrução, hegemonia e democracia: o pós-marxismo de Ernesto Laclau. São Paulo; Recife; Buenos Aires [versão digital]: INPSO, Instituto de Pesquisas Sociais; FUNDAJ, Fundação Joaquim Nabuco; Consejo Latinoamericano de Ciencias Sociales (CLACSO), 1997.

BURITY, Joanildo A. Religião e Política na Fronteira: desinstitucionalização e deslocamento numa relação historicamente polêmica. Revista de Estudos da Religião, n. 4, pp. 27-45, 2001.

BURITY, Joanildo A. Republicanismo e o crescimento do papel público das religiões: comparando Brasil e Argentina. Contemporânea, v. 1, n. 1, pp. 199-227, 2011.

BUTLER, George. Northern Brazil. The Missionary, Richmond (EUA), p. 151, abril de 1890.

BUTLER, George. The Fifteenth of November, The Missionary, Richmond (EUA), p. 134, abril de 1890.

CARVALHO, José Murilo de. A formação das almas: o imaginário da República no Brasil. São Paulo: Companhia das Letras, 1990.

COSTA, Milton Carlos. D. Antônio de Macedo Costa: uma teologia do poder. Revista Brasileira de História das Religiões, ANPUH, v. 9, n. 25, pp. 07-22, 2016.

CUNHA, Luiz Antônio. A Educação Brasileira na Primeira Onda Laica: do Império à República. Rio de Janeiro: Edição do Autor, 2017.

EXTREMOS QUE SE TOCAM. O Apóstolo, Rio de Janeiro, p. 2, 18 dez. 1889.

FRESTON, Paul. Estado laico e evangélicos na política brasileira: controvérsias atuais em perspectiva. In: Ultimato, n. 351, Nov.-dez 2014. Disponível em: http://www. ultimato.com.br/revista/artigos/351/estado-laico-e-evangelicos-na-politica-brasileira-controversias-atuais-em-perspectiva. Acesso: 15 ago. 2020.

GAZETILHA. O Globo, São Luís, p. 3, 23 dez. 1889.

GIUMBELLI, Emerson. O Fim da Religião: dilemas da liberdade religiosa no Brasil e na França. São Paulo: Attar Editorial, 2002.

GIUMBELLI, Emerson. Religião e Espaço Público no Caso do Cristo no Júri: Rio de Janeiro, 1891. Acervo: Revista do Arquivo Nacional, Rio de Janeiro, v. 16, n. 2, pp. 19-42, 2003.

GIUMBELLI, Emerson. A presença do religioso no espaço público: modalidades no Brasil. Religião e Sociedade, Rio de Janeiro, v. 28, n. 2, pp. 80-101, 2008.

O GLOBO, Rio de Janeiro, p. 3, 27 nov. 1889.

GOVERNO PROVISORIO DO ESTADO do Maranhão. O Globo, São Luís, p. 2, 7 dez. 1889.

HERMAN, Jacqueline. Religião e política no alvorecer da República: os movimentos de Juazeiro, Canudos e Contestado. In: FERREIRA, Jorge; DELGADO, Lucília de Almeida N. (Orgs.). O Brasil Republicano: o tempo do liberalismo excludente (18891930). Vol. 1. Rio de Janeiro: Civilização Brasileira, 2003. pp. 121-160 
LAVELEY, Emílio de. Do futuro dos povos católicos. Tradução do Dr. Miguel Vieira Ferreira. Rio de Janeiro: BORSOI, 1944.

LEVI, Giovanni. Sobre a micro-história. In: BURKE, Peter (Org.). A Escrita da História: novas perspectivas. Tradução de Magda Lopes. São Paulo: UNESP, 1992. pp. 133-161.

LIMA, Carlos de. História do Maranhão: a República. 2a Ed. São Luís: Instituto Geia, 2010a.

LIMA, Sergio Prates. Peregrinos, missionários e protestantismo: o caso de Robert Reid Kalley. Dissertação (Mestrado em Ciências) - Instituto de Ciências Humanas e Sociais, Universidade Federal Rural do Rio de Janeiro. Seropédica, 2010b.

MARQUES, Astôlfo. A Nova Aurora: novela maranhense. [s.n.]: Tipografia Teixeira, 1913.

MARIANO, Ricardo; GERARDI, Dirceu André. Eleições presidenciais na América Latina em 2018 e ativismo político de evangélicos conservadores. Revista USP, $\mathrm{n}$. 120, pp. 61-76, 2019.

MENDES, Teixeira Raimundo. Religião da Umanidade, Gazeta de Notícias, Rio de Janeiro, p. 02, 28 dez. 1889.

MENDONÇA, Antônio Gouvêa. O Celeste Porvir: a inserção do protestantismo no Brasil. São Paulo: Aste, 1995.

MONTERO, Paula. Max Weber e os dilemas da secularização: o lugar da religião no mundo contemporâneo. Novos Estudos CEBRAP, 65, pp. 34-44, 2003.

MONTERO, Paula. Secularização e espaço público: a reinvenção do pluralismo religioso no Brasil. Revista Etnográfica, v. 13, n. 1. pp. 7-16, 2009.

MONTERO, Paula. Controvérsias religiosas e esfera pública: repensando as religiões como discurso. Religião e Sociedade, Rio de Janeiro, v. 32, n. 1, pp. 167-183, 2012.

MONTERO, Paula (Org.). Religiões e controvérsias públicas: experiências, práticas sociais e discursos. São Paulo; Campinas, SP: Editora Terceiro Nome; Editora Unicamp, 2015.

MOURA, Sérgio Lobo de; ALMEIDA, José Maria Gouvêa de Almeida. A Igreja na Primeira República. In: FAUSTO, Boris (Org.). O Brasil republicano: sociedade e instituições (1889/1930). T. III. Vol. 2 (Coleção HGCB). Rio de Janeiro: Bertrand Brasil, 1990. pp. 348-370.

PARTE AMANHÃ PARA... O Globo, São Luís, p. 2, 8 jan. 1890.

PIERUCCI, Antônio Flávio. Secularização em Max Weber: da contemporânea serventia de voltarmos a acessar aquele velho sentido. Revista Brasileira de Ciências Sociais, São Paulo, v. 13, n. 37, pp. 43-73, 1998.

REVEL, Jacques (Org.). Jogos de escalas: a experiência da microanálise. Tradução de Dora Rocha. Rio de Janeiro: Editora Fundação Getúlio Vargas, 1998.

RIBEIRO, Boanerges. Protestantismo no Brasil Monárquico, 1822-1888: aspectos culturais de aceitação do protestantismo no Brasil. São Paulo: Pioneira, 1973. 
SEPARAÇÃO DA IGREJA DO ESTADO. Gazeta de Notícias, Rio de Janeiro, p. 01, 29 dez. 1889.

TAVARES JUNIOR, Pedro. O ex-governador do Maranhão ao Publico, Gazeta de Notícias, Rio de Janeiro, p. 3, 28 jan. 1890.

TAVARES JUNIOR, Pedro. O ex-governador do maranhão ao Publico. Gazeta de Notícias, Rio de Janeiro, p. 3, 30 jan. 1890.

TAVARES, João Luiz. Publicações Solicitadas. O Globo, São Luís, p. 3, 28 dez. 1889.

VÉRAS, Rogério de Carvalho. O arquiteto das orquídeas: trajetória e memória de George William Butler, médico e missionário protestante no Nordeste da aurora republicana (1883-1919). 2018. 391 p. Tese (Doutorado em História). Universidade Estadual Paulista (UNESP), Faculdade de Ciências e Letras, Assis, 2018.

VIEIRA, David Gueiros. O Protestantismo, a Maçonaria e a Questão Religiosa no Brasil. Brasília: UNB, 1996.

TROELTSCH, Ernst. El protestantismo y el mundo moderno. $2^{\text {a }}$ Ed. México, D.F.; Buenos Aires: Fondo de Cultura Económica, 1958.

\section{NOTAS}

${ }^{1}$ Tomo como referência para uma análise deste processo histórico e contemporâneo Paula Montero (2003, 2009, 2012, 2015), Emerson Giumbelli (2002, 2003, 2008) e Joanildo Burity (2001, 2011).

${ }^{2}$ Este corolário é próprio dos estados liberais. Ressalte-se que, por razões ideológicas distintas, estados autoritários, ao longo do século XX, impuseram uma secularização antirreligiosa e intransigente.

${ }^{3} \mathrm{O}$ cientista político turco Ahmet Kuru propõe uma tipologia, em continuum, das relações Estado-Igreja no mundo contemporâneo: 1- Estados religiosos (ex.: Irã); 2- Estados com uma religião estabelecida (ex.: Inglaterra) ou com várias religiões estabelecidas ou oficializadas (ex.: Indonésia); 3- Estados com a "laicidade passiva" ou "plural", ou seja, a neutralidade estatal permitindo a visibilidade pública da religião (ex.: EUA); 4- Estados com a "laicidade agressiva" ou "de combate", ou seja, que exclui a religião da esfera pública (ex.: França, Turquia); 5- Estados antirreligiosos (ex.: Coreia do Norte) (apud Freston, 2014).

${ }^{4}$ Seguindo Luiz Antônio Cunha, ao definir que "o processo de secularização se refere à cultura e o de laicidade, ao Estado” (Cunha, 2017, p. 13), concordo que tal distinção pode ser operacional para compreendermos como Estado e sociedade assumem diferentes tipos de arranjo com as religiões.

${ }^{5}$ Nesse sentido, é emblemática a conclusão de Roque Spencer M. de Barros sobre a conjuntura que levou à chamada Questão Religiosa, em cujo subtítulo traz Maré em favor do Estado laico: "Em uma palavra, aqui e ali, o sistema da religião oficial ia sendo aos poucos minado, para atender as reivindicações da consciência moderna." (Barros, 1997, p. 336). 
${ }^{6}$ Ver, por exemplo, Bruneau (1974), Azzi (1976), Moura e Almeida (1990) e Costa (2016).

${ }^{7}$ Os historiadores do protestantismo têm afirmado a importância da inserção protestante no Brasil para o processo de laicização do Estado por meio da gradual ampliação dos direitos civis e políticos dos acatólicos (liberdade religiosa, secularização dos cemitérios, direito de exercer cargos eletivos, casamento civil etc.) desde o início do Império. Ver: Ribeiro (1973), Vieira (1996) e Lima (2010b).

${ }^{8}$ Como afirma o historiador Jacques Revel (1998), ao micro-historiador cabe o "jogo de escalas", isto é, o esforço em alternar a lente objectiva, indo do detalhe ao panorama, do indivíduo à sociedade, evitando construir dicotomias que privilegiem determinantes, pois essas causalidades não se excluem, mas interagem criativamente na especificidade de cada local/indivíduo.

9 A estimativa de mortos varia de dois a quatro entre os diferentes narradores (O Globo, 1889, p. 3). Sobre este levante, ver também Marques (1913) e Lima (2010a).

${ }^{10}$ Em 28 de janeiro de 1890, na Gazeta de Notícias do Rio de Janeiro, depois de sua exoneração, o ex-governador do Maranhão Pedro Tavares Junior publicou os telegramas trocados com as autoridades do governo federal entre 23 dez. 1989 e 08 jan. 1990, como "methodo novo nas lutas e discussões políticas entre nós", dizendo-se "victimado pelo arbítrio e pela precipitação dos que se assenhorearam dos destinos do paiz e hoje regem esses destinos com as sem ceremonias do primitivo direito dominical romano" (Tavares Junior, 1890, p. 3).

11 A frase de Pedro Tavares pode ser entendida como uma paráfrase da famosa frase dos republicanos decepcionados com o novo regime no Brasil: "não era esta a República com que sonhara” (Tavares Junior, 1890, p. 3).

${ }^{12}$ No original: "We have been somewhat sorely anxious about the Liberty of Worship bill, as it involves the permanence in or dismission from government offices of a good number of our church people and friends" (Butler, 1890, p. 151). Todas as traduções deste artigo são de nossa autoria.

${ }^{13}$ No original: "January 10. The church was separated from state, equality of worships proclaimed, and subversion (subsidy) to any religion prohibited. Congratulations. Duarte" (Butler, 1890, p. 151).

${ }^{14}$ No original: "The State of Maranham tried to take the lead in separation of church and state, but the central government overruled and rescinded our action" (Butler, 1890, p. 134).

${ }^{15}$ Conforme José Murilo de Carvalho (1990, p. 22), na transição para o novo regime havia três modelos disponíveis de República para os republicanos brasileiros, "dois deles, o americano e o positivista, embora partindo de premissas totalmente distintas, acabavam dando ênfase a aspectos de organização do poder. O terceiro colocava a intervenção popular como fundamento do novo regime, desdenhando os aspectos de institucionalização". Havia entre os próprios positivistas os ortodoxos do grupo de Laffitte, "que não aceitavam o parlamentarismo adotado pela Constituição Francesa de 1875 e se impacientavam com a demora no rompimento das relações entre a Igreja e o Estado e com a timidez das políticas educacionais [...], 
ainda adotavam a ideia da ditadura republicana desenvolvida por Comte", enquanto os heterodoxos do grupo de Littré "aceitava[m] o parlamentarismo [...], e admitia[m] compromissos em torno de questões importantes, como o das relações entre Estado e Igreja, em nome do oportunismo - isto é, em termos positivistas, em nome da necessidade de aguardar o momento sociológico adequado para intervir". Havia ainda uma variante nessas duas vertentes introduzida por Comte após 1845, na qual "os elementos religiosos passaram a predominar sobre os aspectos científicos, o sentimento foi colocado acima da razão, a comunidade foi sobreposta ao indivíduo" (Carvalho, 1990, pp. 20, 21).

${ }^{16}$ É interessante se observar que, embora o decreto 119-A (cuja redação deve-se principalmente a Ruy Barbosa) tenha se inspirado na Constituição dos Estados Unidos, a sequência temática dos seus dispositivos se assemelha à estrutura da redação do decreto emitido pelo governador do Maranhão, Pedro Tavares Júnior: inicia-se pela garantia da liberdade de consciência; em seguida, estabelece a igualdade de cultos, garantindo aos fiéis que não sejam molestados, e termina com os dispositivos que expressam o desejo de extinção do padroado. Para uma análise do decreto 119-A, ver Giumbelli, 2002.

${ }^{17}$ Após as leis do Maranhão, entre os dias 26 de dezembro de 1889 e 07 de janeiro 1890, nos jornais, encontramos várias notícias de reuniões de clubes republicanos, meetings envolvendo políticos e governadores locais para pressionar e/ou demonstrar apoio à decisão do governo provisório central de instituir a separação Igreja-Estado (até então, ainda não efetivada). Cunha (2017, p. 402), servindo-se do jornal Imprensa Evangélica de 04 de janeiro de 1890, resume bem o crescimento dessas pressões: "De Maceió (AL), onde se realizou comício promovido pelo Centro Republicano em favor da ideia de liberdade de culto e da necessidade de separação entre a Igreja Católica e o Estado; de Santos (SP), anunciando a reunião para pedir ao Governo Provisório essa separação; de Desterro (SC), comunicando o apoio do Clube Republicano, da Associação Comercial, da Sociedade Beneficente Comercial e das forças de terra e de mar, a telegrama (sic) ao Governo Provisório pedindo que a Igreja e o Estado se separassem.."

${ }^{18}$ Já no dia 18 de dezembro, o jornal católico O Apóstolo, do Rio de Janeiro, repercutiu ironicamente os atos da junta governativa do Maranhão (que incluía a liberdade de cultos e a extinção de verbas ao culto católico), lustrando-os como atos de violência cometidos contra seus próprios aliados e contra a Igreja: "Ora viva o Maranhão, e morram os soldados, que não sabiam que republica era guerra a Deus e a sua Egreja" (Extremos que se tocam, 1889, p. 2). No dia 28 de dezembro, o maranhense Teixeira Mendes, um dos fundadores da Igreja Positivista do Brasil, discorrendo sobre o decreto do governador Pedro Tavares de separação Igreja-Estado e argumentando com base no princípio federativo, opinou que: "estamos convencidos e o temos sempre sustentado, que os Estados brasileiros devem decretar a separação da Igreja e do Estado, como medida garantidora da Ordem e Progresso". Mais adiante: "O ato do Governador do Maranhão foi, portanto correto. Trata-se de um Estado onde não ha o menor espirito clerical, e onde o ato passaria sem o mínimo protesto si o governador ouvésse mantido os subsidios dos atuaes funcionarios ecleziasticos, cujas funções politicas ficarão suprimidas, conforme o determina a Politica Pozitiva." (Mendes, 1889, p. 02). No dia seguinte, no mesmo jornal da capital da República publicou-se, sob o 
título "SEPARAÇÃO DA IGREJA DO ESTADO", a notícia da anulação do decreto do governador Pedro Tavares por ordem do marechal Deodoro e que tal medida causou geral surpresa, pois "O decreto do governador apenas consentia templos de qualquer religião, sem forma exterior de templo, e extinguia as verbas para pagamento de sacristães, capellães e confessores." (Separação da Igreja do Estado, 1889, p. 01).

${ }^{19}$ Como foi bem percebido por Mariano e Gerardi (2019, p. 64): "Por séculos, a historiografia, a sociologia e a propaganda protestante vincularam o protestantismo aos valores da igualdade, liberdade e autonomia individual.... Todavia, tal percepção, relacionando diretamente a inserção do protestantismo no Brasil e na América Latina à promoção dos valores modernos, e contribuindo para a superação dos seus arcaísmos e subdesenvolvimento, "parece refletir mais preconceitos etnocêntricos sobre a região, sua população e sua religião dominante do que se basear numa análise empírica sobre as consequências da expansão evangélica em si". Nesse sentido, as fontes que analisamos nesta pesquisa revelam que a retórica modernizadora dos agentes do protestantismo, desde o início, mal disfarçava um ativismo e um projeto político contraditórios aos valores da modernidade.

${ }^{20}$ No original: "To plant in the very heart of a free Protestant nation a Romish university, alias, the symbol of mental and political slavery, is something not easily forgotten" (Butler, 1890, p. 134).

${ }^{21}$ No original: "If lovers Christian liberty deplore the advances of the papacy in Washington, in Brazil they rejoice with great and exceeding joy over the loss of monarchical and papal power. We are fully aware that the victory is not complete, but it will inevitable come" (Butler, 1890, p. 134).

${ }^{22}$ No original: "Just as I close, the news comes of the separation of church and state - the equality of religions" (Butler, 1890, p. 134).

${ }^{23}$ Sirvo-me da noção de hegemonia seguindo de perto o sentido gramcsiano do termo: "Com Gramsci a hegemonia, ao passar do terreno 'político' (no sentido leninista) para o da liderança 'intelectual e moral', amplia-se para além de sua referência puramente classista (alianças de classes), na medida em que exige um certo 'consenso' em torno de 'idéias' e 'valores' que atravessem posições de classe, produzindo uma nova vontade coletiva. Esta, por meio da ideologia, se torna assim o cimento orgânico unificador de um 'bloco histórico'. A ideologia - não mais vista como 'sistema de idéias' ou como 'falsa consciência', mas como força material, 'um todo orgânico e relacional, encarnado em instituições e aparelhos, que solda um bloco histórico em torno de uma série de princípios articulatórios básicos' - torna-se o terreno por excelência em que as relações entre os diversos componentes de uma nova vontade coletiva se formam." (Burity, 1997, p. 12, grifo do autor).

${ }^{24}$ Mendonça (1995, p. 77) descreve um dos fundamentos dessa ideologia missionária norte-americana: "A ideia de que a Igreja Católica era portadora e legitimadora de regimes políticos antagônicos aos ideais norte-americanos podia justificar uma grande preocupação com a América Latina, que se apresentava como um grande bloco oficialmente católico. Apesar de que os sucessivos movimentos de independência vão, na América espanhola, partindo para regimes republicanos, a presença da Igreja Católica não era tranquilizadora, 
pois ela tendia a forçar a reprodução da sociedade hierárquica independentemente do regime político.. Um dos livros que mais influenciou os agentes protestantes no Brasil foi Do futuro dos Povos Católicos, do católico belga Emílio de Laveley. Editado pela primeira vez em 1875, em francês, foi traduzido pelo pastor maranhense Miguel Vieira Ferreira em 1889. Na obra, Laveley, muito antes da tese de Max Weber, associa o progresso econômico e os princípios democráticos dos países anglo-saxões ao protestantismo, afirmando sua superioridade civilizatória em relação ao catolicismo (Laveley, 1944).

25 "Um governo criterioso não pode deixar de attender às condições peculiares do povo, que governa; respeita seus costumes, tradições e crenças, e não vai de chofre atacar os sentimentos mais delicados da alma nacional" (A Religião do Estado, 1890, p. 1).

26 "Desde os primeiros dias do advento da Republica, ocorreram uns rumores de separação da Igreja do estado, de casamento civil e outras reformas funestas, que são exigidas pelas seitas enraizadas no Brazil e pelos políticos chamados adiantados" (A Religião do Estado, 1890, p. 1).

${ }^{27}$ Ver: Azzi (1976), Moura e Almeida (1990), Herman (2003) e Costa (2016).

${ }^{28}$ Predomina uma interpretação deste processo como uma disputa e uma negociação entre republicanos, positivistas ortodoxos, anticlericais e o clero ultramontano. Ver: Moura e Almeida (1990), Carvalho (1990), Azzi (1976) e Bruneau (1974). Mais recentemente, alguns autores têm destacado a importância dos protestantes na conformação do espaço público republicano nos anos iniciais do novo regime. Ver: Giumbelli (2002, 2003), Cunha (2017).

${ }^{29}$ Segundo Ducan Reily (2003, pp. 224, 225), o decreto n. 119-A estabeleceu a extinção do padroado e a garantia da "plena liberdade religiosa", situação que não foi "aceita passivamente pelos católicos, os quais, de tempos em tempos, pressionavam em seu favor - atitude interpretada pelos protestantes como quebra do princípio de separação entre Igreja e Estado". É conhecido que, embora a Igreja Católica não obtivesse privilégios formais pela Constituição de 1891, na prática, as relações com o Estado Republicano tenderam à acomodação dos interesses da Igreja. Em muito contribuiu para isso uma legislação pouco precisa dos limites e do lugar da religião no novo regime. Nesse sentido, mais recentemente, alguns autores (Giumbelli, 2002; Leite, 2011) têm destacado que o próprio texto constitucional de 1891, no campo doutrinário (do debate entre os juristas da época) permitia interpretações distintas, indefinições e dubiedades quanto à laicidade do Estado brasileiro, possibilitando a conciliação do Estado com a Igreja Católica antes mesmo de qualquer rearticulação do catolicismo, como, por exemplo, na publicação da Carta Pastoral de D. Sebastião Leme em 1916. Tal indefinição foi mantida nas constituições posteriores e permanece, em linhas gerais, até hoje legitimando a aproximação entre Estado e religião.

${ }^{30}$ Desde os projetos da constituição de 1891, a Igreja Católica conseguiu uma série de normas constitucionais ou infra-constitucionais as quais relativizavam o radicalismo inicial da separação, abrindo a possibilidade de (re)acomodação entre o catolicismo e o Estado, e permaneceram nas constituições seguintes até à atual (por exemplo: ensino religioso). Estas mesmas normas que, na maior parte da história brasileira, favoreceram a aliança da Igreja Católica com o Estado, em diversos momentos de crise dessa relação permitiram que 
também os protestantes pudessem vir a compor com o Estado, ou mesmo a substituir o catolicismo como aliado preferencial (como em parte considerável da ditadura, 19641985). Não por acaso, nesses momentos, os protestantes passam de teóricos defensores do Estado Laico à, na prática, legitimadores do poder estatal e, exatamente por isso, retomam seu projeto nunca abandonado de submeter a cultura e a sociedade brasileiras à sua versão da lei divina (Troeltsch, 1958).

Artigo submetido em 31 de agosto de 2020.

Aprovado em 17 de agosto de 2021.

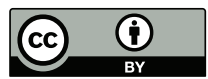

